\title{
Cultura Visual: Rumo \\ à Compreensão de \\ Outros Universos no \\ Ensino de Artes
}

Thais Paulina Gralik

nupeart 
Este artigo faz uma reflexão sobre fatores e pensamentos que vêm provocando mudanças e novas tendências no ensino das Artes Visuais. A Arte como expressão, percebida e valorizada apenas como meio para o desenvolvimento pessoal e da criatividade, largamente difundida na modernidade, cede lugar a um fazer artístico consciente e elaborado, associado à compreensão crítica de imagens da Cultura Visual devidamente contextualizadas. Os modelos das culturas únicas da arte erudita estão sendo questionados como objeto de estudos. Por necessidade de associar o ensino de Artes aos problemas da atualidade, estes fundamentos vêm sendo substituídos em função de uma educação intercultural, crítica e democrática. Muda-se a ênfase na cultura de sentido único e singular para a multidirecional, que leva aos estudos críticos sobre a Cultura Visual.

\title{
Introdução
}

\begin{abstract}
A tendência educativa no ensino de Arte atual (pós-modernista) no ABrasil, grande parte difundida por Barbosa (2003), tem sofrido mudanças e enfatizado a "interrelação entre o fazer, a leitura da obra de Arte (apreciação interpretativa) e a contextualização histórica, social, antropológica e/ou estética da obra" (Barbosa, 2003, p.17). Esta é uma das orientaçóes principais, que tem levado uma boa parte dos arte-educadores a direcionar o ensino de Artes sobre os principais artistas e movimentos artísticos de diferentes partes do mundo, europeus, norte-americanos e brasileiros.
\end{abstract}

Quatro conceitos chaves da modernidade cultural que se entrelaçaram como a modernidade estética que chegaram a converter-se em destacados mecanismos educativos: epistemologia, identidade social, localização e saúde psicológica, conceitos que tem configurado o currículo e determinado o sentido de informação que constitui seu conteúdo (Efland, 2003, p.44, tradução nossa). 
A educação moderna muito arraigada entre nós, segundo Barbosa (2003) e Efland (2003), comprometia-se anteriormente, até os inícios dos anos 80, com o desenvolvimento da expressão pessoal do aluno e com as leituras de obras de Arte baseadas no pensamento formalista e a-social de análise. Podemos entender que:

A elaboração de uma filosofia caracterizada por uma análise a-social, formal, e quase-científica da arte adquiriu grande importância para a comunidade da arte. As representaçôes científicas das preocupaçóes formais e expressivas da comunidade da arte tomaram ao menos duas formas controvertidas no pensamento moderno. Em arte se concebeu como objetivo (em termos de uma ciência formalista) e subjetivo (de acordo com a caracterização da psicologia de um artista infantil, mitológico, genérico e livremente expressivo) (Efland, 2003, p.41, tradução nossa).

O enfoque acentuado no fazer (experimentar) em Arte acarretou em um ensino superficial, baseado no ensino de técnicas, que não permitia construir os sentidos necessários para que os alunos pudessem perceber e compreender os significados da Arte, relacionamentos entre Arte e cultura, diversidade das culturas e a própria identidade. $\mathrm{O}$ conceito moderno de identidade baseou-se na absoluta particularidade do sujeito, centrando-se na idéia de individualismo. Neste contexto, a história se apercebia como uma acumulação de atos individuais de expressão encarnados em objetos feitos por pessoas de "gênio", supostamente inatos, pertencentes a determinadas classes sócio-econômicas, e vistos como alheios a interesses sociais, econômicos ou políticos. E, segundo Efland (2003), enquanto promovem a expressão autônoma na produção artística das escolas, os currículos ainda mantêm a noção de individualismo.

No final da Segunda Guerra Mundial, a escola perpetuou o medo causado pelas características autoritárias da guerra. Em conseqüência disso, passou-se a considerar como patológico se professor e/ou aluno fossem portadores dessas caracte-rísticas, e os psicólogos profissionais trabalharam para ajudar o público em geral e aos educadores para prevenir estes traços nas crianças. "A tensão entre a veneração por uma epistemologia de certezas e os temores que suscitava 
o autoritarismo forta-leceu a vertente terapêutica da escola de arte" (Efland, 2003, p.43, traduçáo nossa).

O pensamento moderno também contribuiu para a crença da universalidade da Arte, de uma Arte de nível "superior", levando os museus, e o ensino de Arte, a considerarem apenas as estéticas eruditas de código alto. A crença surgida da supremacia do Ocidente, segundo Efland (2003), surge das formas territoriais estáveis que abrigavam culturas estanques em seus limites naturais. Decorrente ainda da concepção modernista, uma visão evolucionista da história social, a sociedade sempre progrediu para formas melhores, e em paralelo com o avanço da ciência, perfeccionismo tecnológico e aumento das liberdades. Culminando com o pensamento ainda vigente que situa os Estados Unidos como centro da Arte mundial.

Desde as ciências sociais norte-americanas apresenta-se freqüentemente os Estados Unidos como o ator paradigmático deste avanço histórico. Em muitos âmbitos (econômico, político, cultural, etc.) as disciplinas profissionais norte-americanas encerram uma visão complacente do progresso e a fé no papel salvífico desta nação, destinada a trazer prosperidade e civilização ao resto do mundo" (Efland, 2003, p.42, tradução nossa).

Entretanto a comunidade artística norte-americana, mais entregue ao mercantilismo, "não parece em absoluto estar interessada na livre competição internacional" (Efland, 2003, p.42). Há um crescente aumento do poder empresarial americano atual que se expande em todos os aspectos do cotidiano em muitos países, incluindo o nosso, contribuindo para uma grande proliferação de produção de imagens que, em sua maioria, visam a que os jovens se tornem consumidores. Este seria um dos motivos pelo qual testemunhamos hoje uma forte tendência de associar o ensino de Artes com a Cultura Visual (Barbosa, 2003). O universo visual hoje é extremamente persuasivo, e vivemos em uma época onde as corporaçóes multinacionais atuam como forças na cultura das mídias. A natureza da cultura infantil está sendo transformada pela cultura empresarial, e este fato "torna-se claro à medida que as fronteiras que eram mantidas entre as 
esferas da educação formal e do entretenimento entram em choque" (Giroux, 2000, p.127).

\section{Transformações no Ensino de Artes}

$\mathrm{R}$ evendo os conceitos modernistas, arte-educadores passaram a Rquestioná-los e a incluir mudanças significativas no ensino de Artes. O método da livre expressão foi muito utilizado em arte-educação como meio para liberar a emoção e desenvolver a criatividade individual. Este conceito modernista que via na expressão pessoal, uma possibilidade de todo ser humano ser um artista em potencial, sacralizado pelas teorias psicanalíticas da Arte, "foi substituído pela idéia de que todos podemos compreender e usufruir da Arte" (Barbosa, 2003, p.17).

A intençâo de se desenvolver a sensibilidade e criatividade do aluno ampliou-se objetivando atingir um maior desenvolvimento cultural do aluno. A Arte na educação como expressão pessoal e como cultura para Barbosa é:

Um importante instrumento para a identificaçáo cultural e o desenvolvimento individual. Por meio da Arte é possível desenvolver a percepção e imaginaçáo, apreender a realidade do meio ambiente, desenvolver a capacidade crítica, permitindo ao indivíduo analisar a realidade percebida e desenvolver a criatividade de maneira a mudar a realidade que foi analisada (Barbosa, 2003, p.18).

Acreditava-se, de acordo com o pensamento modernista, que bastava fornecer ao aluno as técnicas para que este as devolvesse em forma de trabalhos artísticos de maneira criativa. Assim, valorizava-se ao máximo a originalidade e a expressão individual. Já no pen-

\footnotetext{
${ }^{2}$ Para David Perkins (1999) o desempenho flexível está relacionado com a compreensão. Compreender um tópico quer dizer "ser capaz de desempenhar-se flexivelmente em relação ao tópico: explicar, justificar, extrapolar, vincular e aplicar de maneira que vá mais além do conhecimento e a habilidade rotineira [...] é questáo de ser capaz e atuar com flexibilidade a partir do que se sabe. A capacidade de desenvolvimento flexível é a compreensão" (p.73, traduçấo nossa).
} 
samento pós-moderno passou-se a valorizar mais a elaboração e a flexibilidade ${ }^{2}$.

Considerando a leitura de obras de Arte na escola, tem havido algumas implicaçóes para se refletir neste contexto. A implicação causada pelo pensamento formal na leitura, e a escolha centrada em imagens de obras tradicionais, ou como diz Barbosa (2003), as de código alto, ou eruditas de conteúdo universal (determinadas pelo pensamento moderno), fazem parte das consideraçóes a serem pensadas no contexto.

A leitura do discurso visual, na educação que vem tentando se fortalecer na contemporaneidade "não se resume apenas à análise de forma, cor, linha, volume, equilíbrio, movimento, ritmo, mas principalmente é centrada na significação que esses atributos, em diferentes contextos, conferem à imagem" (Barbosa, 2003, p.18). Não mais apenas se preocupando, ou perguntando o que o artista quis dizer, mas sim o que a obra nos diz, em nosso contexto e em outros contextos históricos. Ao caráter formalista da leitura da obra acrescentou-se um meio de acesso à significação dos conteúdos através da interpretação contextualizada.

A crítica da obra de Arte, no pensamento moderno, baseava-se nos seguintes aspectos: "disposiçâo de linhas, cores, formas e texturas; realismo e proporção; uso de materiais; e expressividade (de acordo com as idéias preconcebidas de <<correção ou exatitude >> definidas pelos experts)" (Chalmers, 2003, p.48, tradução nossa), o que pressupunha a escolha de obras determinadas pela cultura associadas aos cânones pré-estabelecidos da Arte ocidental dominante. Algumas idéias concretizadas pelo pensamento moderno acerca de Arte ligadas à cultura, determinavam certas obras como sendo a melhor arte:

A melhor arte do mundo tem sido realizada pelos europeus; As pinturas a óleo, a escultura (em mármore ou bronze e a arquitetura monumental são as formas artísticas por excelência; Existe uma distinção hierárquica significativa entre arte e artesanato; A melhor obra tem sido a obra feita por homens; A melhor arte tem sido criada por gênios individuais; [...] A arte por excelência exige uma resposta estética individual; o significado sociocultural é secundário (Chalmers, 2003, p.48, tradução nossa). 
Perceberam os arte-educadores nessas colocaçóes, que o que foi estabelecido pelos cânones ocidentais fazia com que fosse excluída a Arte realizada por outros grupos. Esses fatores, intimamente ligados à noção de cultura que herdamos ao longo dos últimos séculos levantaram em diversas áreas, discussões a respeito da noção do conceito moderno de cultura. Passou-se a questionar o conceito, o que acarretou nas últimas décadas em ressignificaçóes, em muito causadas pelos embates relacionados à diferença e entre os diferentes, e opressão de grupos dominantes sobre os demais. Por essas razóes assistimos "um crescente interesse pelas questóes culturais, seja nas esferas acadêmicas, seja nas esferas políticas ou da vida cotidiana [...] parece crescer a centralidade da cultura para pensar o mundo" (Veiga-Neto, 2003, p.5). Entre os arte-educadores da atualidade, relaçóes entre Arte e cultura, também têm adquirido mais importância desde que:

A Pós-Modernidade abriu portas à importância de entender a arte como representação de significados cuja interpretação depende mais da compreensão de códigos simbólicos e convençôes culturais que circulam nos contextos de origem da obra (do que aproximaçóes formalistas) (Hernández apud Franz, 2004, p.3).

Entender as noçóes do conceito e significaçóes da cultura auxilia também a compreender algumas mudanças ocorridas no ensino de Artes, assim como multiculturalismo, que, por exemplo, foi uma das respostas do pensamento pós-moderno ao monoculturalismo da modernidade, além das leituras contextualizadas que se diferenciam das leituras de caráter formalista, e recentemente uma maior predisposição a se incluir estudos da Cultura Visual em Arte.

É importante salientar que a modernidade centrou-se em uma base comum de onde se partia para pensar a cultura e a educação. Cultura significava:

Tudo aquilo que a humanidade havia produzido de melhor [...] Nesse sentido, a Cultura foi durante muito tempo pensada como única e universal. Única porque se referia àquilo que de melhor havia sido produzido; universal porque se referia à humanidade, um conceito totalizante [...] Assim, a Modernidade esteve por longo tempo mergulhada numa epistemologia monocultural (Veiga-Neto, 2003, p.7). 
No século XVIII originou-se uma diferenciação entre alta e baixa cultura, a partir do momento que "alguns intelectuais alemáes passaram a chamar de Kultur a sua própria contribuição para a humanidade" todo um conjunto de coisas em que eles se consideravam superiores (Veiga-Neto, 2003, p.7). Desde essa época, a cultura passou a ser entendida como algo elevado e único, e a alta cultura tomada como modelo para as demais. $\mathrm{Na}$ educação isso se refletia numa busca em atingir um ideal de formas mais elevadas da cultura baseado em modelo já configurado ou convencionado por determinados grupos.

Somente após haver sérios questionamentos no conceito moderno de cultura em diversas esferas, acadêmicas artísticas e políticas, que passou a existir maior possibilidade de se falar em culturas em lugar de cultura com sentido único, ou singular. Do monoculturalismo que colocava "a ênfase no Humanismo e, em boa parte, na estética", passa-se a pensar em multiculturalismo, o que "muda a ênfase para a política" (Veiga-Neto, 2003, p.11). Pensar em educação multiculturalista, significa a possibilidade de uma direção mais democrática para a educação.

O caráter diferenciador, elitista e monocultural do pensamento moderno levou os países do Terceiro Mundo, dos colonizados culturalmente, e das minorias dos Estados Unidos e Europa, nos anos 60 e 70, a pensarem a diversidade e identidade cultural como conteúdos de grande interesse. Quando os movimentos de liberação dos países colonizados, imigrantes e negros americanos passaram a exigir participação, grupos do sistema dominante "passaram a demonstrar a necessidade de respeito e consideração pelas culturas que haviam subjugado e subjulgado" (Barbosa, 1998, p.79). O multiculturalismo passou então a ser considerado pelos movimentos educativos atuais, como necessário para a democratização da educação. Reivindicando uma educação que fortaleça a diversidade cultural e que considere as diferenças.

Neste campo se concentram muitos conflitos na atualidade. Ao que, em arte-educação Barbosa (1998) defende um ensino multicultural que considere a diversidade cultural, mas levando em conta as diferenças. Pois, "procurar uma igualdade sem considerar as diferenças é obter uma pasteurização homogeneizante” (Barbosa, 1998, 
p.80). Levar para a sala de aula um ensino que leva em conta as diferenças, significa promover a interrelação e o entendimento entre indivíduos de diferentes grupos que interagem com outras culturas. É necessário considerar que também fazemos parte na vida cotidiana, de mais de um grupo cultural. Como exemplificado por Barbosa (1998), ela mesma se define como pertencente a diferentes grupos culturais, como por exemplo ser nordestina do ponto de vista da localidade cultural, arte-educadora segundo a ocupação e branca com relação à etnia. Assim podendo pertencer a um determinado grupo dominante, já em outro ser pertencente a um grupo discriminado.

Há um prenúncio de que os problemas da diversidade cultural comecem a ser tratados nas Escolas do Brasil. De uma certa forma, foram incluídos nos Parâme-tros Curriculares Nacionais, editados pelo MEC em 97/98, sendo a multiculturalidade colocada como tema transversal e designada de "pluralidade cultural" (Barbosa 1998, p.89). ${ }^{3}$ Segundo Franz (2004) “o III Fórum Social Mundial em 2003, realizado em Porto Alegre, por exemplo, foi uma destas iniciativas. Um espaço cultural diversificado, aberto ao pluralismo, à diversidade de gênero, etnias, culturas e capacidades diversas" (p.2).

Os defensores da educação multiculturalista também vem se fundamentando na antropologia. Uma ligação que se deve ao fato de que, em Arte, há muito para se ver no universo estético do outro (Barbosa, 1998). Particularmente, em detectar papéis e funçóes da Arte dentro e entre grupos culturais. Para contemplar um ensino multicultural que se efetive de maneira eficiente, é importante potencializar o orgu-lho pela herança cultural em cada indivíduo valorizando as qualidades das diferenças e ao mesmo tempo promover a interação e a reciprocidade (interculturalidade), como estratégia para o crescimento cultural e enriquecimento mútuo.

\footnotetext{
3 Ana Mae Barbosa, contesta o fato de a multiculturalidade ser designada de pluralidade cultural e colocada como tema transversal nos PCNs, pois segundo sua visão trata-se de tema básico.
} 


\section{Cultura Visual no Ensino de Artes}

A problemática da imposição das culturas dominantes também por parte das grandes empresas multinacionais que transformam a cultura. "Seria preciso lembrar, por exemplo, que estamos assistindo a uma onda mundial de imposição do American way of life em nível planetário?" (Veiga-Neto, 2003, p.6).

Para Efland (2005) enquanto o mundo está sendo unido por um único mercado cultural internacional as pessoas podem perder aspectos de sua identidade tradicional. "A concentração do controle sobre os meios de produção, circulação e troca de informação, foi acompanhada pelo surgimento de novas tecnologias" (Giroux, 2000, p.127) áreas onde os jovens aprendem sobre si mesmos e sobre o mundo.

Nosso universo visual hoje é um mediador de valores culturais. Nossas refe-rências estéticas são construídas socialmente, e as relações do sujeito, especialmente crianças e adolescentes, não conhecem barreiras disciplinares frente a esse universo (Hernández, 2000). Os meios de comunicaçấo hoje são educadores privilegiados do público, produzindo o que Steinberg e Kincheloe (2004) chamam de pedagogia cultural. Não é possível ignorar que:

O cinema medeia representaçóes da realidade que joga com as fantasias, os medos ou os fantasmas. Que a publicidade vende representaçóes ideais do eu e amplifica identidades inexistentes. Que a Internet permite substituir o 'real' pelo 'virtual', possibilitando a construção de identidades inventadas e ocasionais [...] e aproximando-se de 'lugares' que expandem e dispersam a própria idéia de informação e de conhecimento (Simpson, apud Hernández, 2000, p.xi).

Parente (2004) observa o fato de que Foucault, Deleuze e Guattari foram acusados de anti-humanismo porque sustentavam que a subjetividade depende "cada vez mais de uma infinidade de sistemas maquínicos, entre eles as tecnologias de informação e comunicação" (p.96). Mas é unânime entre os filósofos que as técnicas 
de comunicação e informação engendram profundas transformaçôes nas subjetividades e "todos concordam que vivemos um tempo de mudanças" (Ibid, p.93). As diferentes formas da mídia e tecnologia se transformaram em forças fundamentais na configuração das subjetividades, modelização de comportamentos, e práticas sociais da caráter homogeneizante. "Imagens massificadas preenchem nossas vidas cotidianas e condicionam nossos mais íntimos desejos e percepçóes" (Giroux, 2000, p.128). Calvino comenta sobre o fato da nossa civilização estar cada vez mais fortemente impregnada de imagens, fazendo com que assimilemos essas imagens de maneira ininterrupta.

Hoje somos bombardeados por uma tal quantidade de imagens a ponto de não podermos distinguir mais a experiência direta daquilo que vimos há poucos segundos na televisão. Em nossa memória se depositam, por estratos sucessivos, mil estilhaços de imagens, semelhantes a um depósito de lixo, onde é cada vez menos provável que uma delas adquira relevo... Estamos perdendo a capacidade de pensar por imagens (Calvino,1990, p.107).

Estas transformaçóes têm profunda repercussão na educação. Para compreendê-las é preciso estudar o "universo visual com que se relacionam os meninos as meninas e os adolescentes e as formas de apropriação [...] que fazem deste universo visual" (Hernández, 2001, p.2).

A noção de Cultura Visual, no ensino de Artes, conforme Hernández (2000) pode proporcionar a compreensão deste universo, se estiver relacionada com os "significados culturais dos artefatos, fatos e sujeitos" (p.134). O autor ainda enfatiza que, é importante o estudo da cultura das mídias, além de outros objetos estéticos e artísticos, visto ser ela capaz de produzir, regular significados, valores e gostos. Significa explorar o papel mediacional que os meios possuem nas representaçóes, valores e identidades.

Reconhecer que elites dominantes possuem e controlam cada aspecto da produçáo cultural "desde a produção de identidades, de representação e de textos, até o controle da produção, circulação e distribuição de bens culturais - não é uma visão nova para os teóri- 
cos dos estudos culturais" (Giroux, 2000, p.132). Mas, igualmente se concorda que há falta e necessidade de análise sobre o papel educacional das mega corporaçóes que, com freqüência colocam o consumo como a única opção de cidadania do sujeito. Isto colocado percebe-se que há uma diferença entre como educam as mídias e como a escola educa, o que gera preocupaçóes constantes em pais e educadores em geral, levando alguns educadores em direção a incluir estudos da Cultura Visual em arte-educação, com o objetivo de proporcionar a reflexão e análise crítica como meio não só para a resistência, mas principalmente para a compreensão deste universo.

\section{Considerações Finais}

Arte-educação voltada para o desenvolvimento da expressão pes-
soal, foi mais valorizada na modernidade. Orientações psicoló-
gicas, que fundamentaram o ensino de Artes, visavam o ajuste do
indivíduo com a sociedade (Read, 1982). ${ }^{4}$ A livre expressão como
fator de liberaçáo dos sentimentos e emoçóes tornou-se um método
bastante generalizado, pois acreditava-se menos na Arte como trans-
missora de significados e mais na Arte como meio para o desenvolvi-
mento da criatividade e equilíbrio psicológico. Este fundamento não
se desfez de maneira integral. Ainda se considera importante a Arte
na educação como meio para o desenvolvimento da expressão pesso-
al e da imaginação, conforme Barbosa (2003). Mas seu uso também
acarretou em um "laissez-faire" mais generalizado ainda, livre e des-
compromissado com o desenvolvimento cultural que tem sido bas-
tante criticado na atualidade.

Aqueles que defendem a Arte na escola meramente para liberar a emoçáo devem lembrar que podemos aprender muito pouco sobre nossas emoçóes se não formos capazes de refletir sobre elas. $\mathrm{Na}$ educação o subjetivo, a vida interior e a vida emocional devem progredir, mas não ao acaso. Se a Arte não é

\footnotetext{
${ }^{4}$ Para Head (1982), a educação estética propicia o desenvolvimento dos sentidos, da inteligência e do raciocínio, e somente na medida em que os sentidos se relacionam harmoniosamente com o mundo exterior é que se constrói uma personalidade integrada.
} 
tratada como um conhecimento, mas somente como um "grito da alma", não estaremos oferecendo uma educação nem no sentido cognitivo, nem no sentido emocional. Por ambas a escola deve se responsabilizar (Barbosa, 2003, p.21).

Isto é, o ensino de Artes não deve apenas visar o desenvolvimento de uma vaga "sensibilidade nos alunos por meio da Arte", mas sim desenvolver a capacidade de compreender, conceber e usufruir Arte, além de "influir positivamente no desenvolvimento cultural dos estudantes” (Barbosa, 2003, p.17). Decorrente disso, o conceito de criatividade tenta se ampliar, não se efetivando apenas através da prática artística (o fazer), mas se desenvolvendo também através das leituras de obras de Arte, por processo criador. Processo que consiste em "desconstruir para reconstruir, selecionar, reelaborar, partir do conhecido e modificá-lo de acordo com o contexto e a necessidade" (Barbosa, 2003, p.18).

As leituras de obras de Arte fundamentadas no pensamento formalista de caráter técnico científico, também passaram a ser questionadas. Essas leituras, além de permanecerem no plano físico da obra, também se limitaram ao estudo de obras de Arte apenas àquelas consideradas como universais, estáveis e únicas, eruditas ou de código alto, tomadas por modelos, assim determinadas pelas culturas dominantes. $\mathrm{O}$ pensamento moderno em arte-educação, limitou-se em muito ao estudo dessas obras, desconsiderando outras culturas, ou culturas minoritárias e o amplo meio visual imagético que convivemos diariamente.

Entretanto hoje, não somente as Artes, mas também o universo visual cotidiano, devido as suas produçóes de significado, influência na transformação das subjetividades, identidades, comportamentos e práticas sociais, também levantaram questionamentos e produziram alteraçóes no ensino de Artes.

O aumento da consciência da importância dos fatores sócio-culturais na produção de qualquer significado tem conseqüências importantes para o ensino em Arte hoje. A arte-educação baseada em uma concepção pósmodernista é potencialmente conectada ao resto da vida, sem limites entre a arte e seu contexto social e cultural de origem (Franz, 2004, p.2). 
Para Hernández (2001), a imensa proliferação de imagens promovidas pelas indústrias do entretenimento e novas tecnologias, além de gerarem preocupação a respeito de seus conteúdos, também criaram inquietaçóes sobre o aumento do número de pessoas incapazes de interpretar imagens. Para este autor, ainda há pouca compreensão sobre o que são, o que querem dizer as imagens e os efeitos que operam nos observadores, apesar do grande aumento de número de debates que já houve, desde a década de noventa, em torno das questóes visuais.

Além dos fatores de influência na vida e sobre os indivíduos, existem outras razóes, que não mencionamos (a fim de delimitar nosso estudo neste texto) para aumentar a tendência de se incluir estudos da Cultura Visual no ensino de Artes. Uma destas razóes, lembra Hernández (2000), está no fato de que o campo das Artes é o que mais contribui "para configurar as representações simbólicas portadoras dos valores que os detentores do poder utilizam para fixar sua visão de realidade" (p.43). O que faz com que os estudos da Cultura Visual sejam direcionados para que os alunos aprendam a selecionar informaçóes e desenvolver estratégias para a compreensão e interpretação crítica do mundo das imagens.

Assim, consideram os defensores desses estudos que, não apenas obras de Arte consideradas canônicas façam parte dos estudos da Cultura Visual, mas também os objetos artísticos, produtos culturais que se produzem no presente, os produzidos pelas mídias, e pelas diferentes culturas.

Salientamos brevemente neste estudo, algumas das principais transformaçóes e preocupaçóes que vêm modificando o ensino de Artes, demonstrando a necessidade da atualidade de se incluir estudos para a educação da Cultura Visual. Mudanças ocorridas pelo pensamento pós-moderno, assim como as ressignificaçóes do conceito de cultura e cultura das mídias, que de alguma forma influenciaram tais transformaçóes, embora haja outros fatores não aqui mencionados, pois esses necessitariam longas exposiçóes à parte. 


\section{Referências}

BARBOSA, Ana Mae. Inquietaçôes e Mudanças no Ensino da Arte. São Paulo: Cortez Editora, 2003.

BARBOSA, Ana Mae. Tópicos Utópicos. Belo Horizonte: C/ Arte, 1998.

CALVINO, Italo. Seis Propostas para o próximo milênio. São Paulo: Companhia das Letras, 1990.

CHALMERS, F. Graene. Arte, educación y diversidad cultural. Barcelona: Ediciones Paidós, 2003.

EFLAND, Arthur D.; FREEDMAN, Kerry; STUHR, Patrícia. La educación en el arte posmoderna. Barcelona: Paidós, 2003.

EFLAND, Arthur D. Cultura, sociedade, arte e educação num mundo pósmoderno. In: GUINSBURG, Jacó; BARBOSA, Ana Mae (Org.) O pósmodernismo. São Paulo: Perspectiva, 2005. p. 173-188.

FRANZ, Teresinha Sueli. Os desafios para uma educação Pós-Moderna. Cadernos de Texto da FUNARTE - Programa de Arte sem Barreiras, Rio de Janeiro, v.4, 2004 Disponível em: <http://www.funarte.gov.br/ asbarreiras/asbpublicacoes.htm> Acesso em 30.10.06.

GIROUX, Henry A. Atos Impuros: A prática politica dos estudos culturais. São Paulo: Artmed, 2000.

HEAD, Herbert. A educação pela arte. São Paulo: Martins Fontes, 1982.

HERNÁNDEZ, Fernando. Cultura Visual, Mudança Educativa e Projeto de Trabalho. São Paulo: Artes Médicas, 2000.

HERNÁNDEZ, Fernando. La necesidad de repensar la educación de las artes visuales y su fundamentación en los estudios de Cultura Visual. Seminário proferido no Congreso Ibérico de Arte-Educación, Porto, Portugal, nov. 2001. 
PARENTE, André (org.). Tramas na Rede: novas dimensöes filosóficas, estéticas e políticas da comunicação. Porto Alegre: Sulina, 2004.

PERKINS, David. Qué es la comprensión? In: WISKE, Martha Stone. La Enseñanza para la Comprensión. Barcelona: Paidós, 1999.

STEINBERG, Shirley R.; KINCHELOE, Joe L. (orgs.). Cultura Infantil: A construção corporativa da infância. Rio de Janeiro: Civilização Brasileira, 2004.

VEIGA-NETO, Alfredo. Cultura, Culturas e educação. Revista Brasileira de Educação, São Paulo, ANPEd, no 23, maio/jun./jul. /ago. 2003. 